\title{
Hydrous mantle transition zone indicated by ringwoodite included within diamond
}

\author{
D. G. Pearson ${ }^{1}$, F. E. Brenker ${ }^{2}$, F. Nestola ${ }^{3}$, J. McNeill ${ }^{4}$, L. Nasdala ${ }^{5}$, M. T. Hutchison ${ }^{6}$, S. Matveev ${ }^{1}$, K. Mather ${ }^{4}$, G. Silversmit ${ }^{7}$, \\ S. Schmitz ${ }^{2}$, B. Vekemans ${ }^{7} \&$ L. Vincze
}

The ultimate origin of water in the Earth's hydrosphere is in the deep Earth-the mantle. Theory ${ }^{1}$ and experiments ${ }^{2-4}$ have shown that although the water storage capacity of olivine-dominated shallow mantle is limited, the Earth's transition zone, at depths between 410 and 660 kilometres, could be a major repository for water, owing to the ability of the higher-pressure polymorphs of olivinewadsleyite and ringwoodite-to host enough water to comprise up to around 2.5 per cent of their weight. A hydrous transition zone may have a key role in terrestrial magmatism and plate tectonics ${ }^{5-7}$, yet despite experimental demonstration of the water-bearing capacity of these phases, geophysical probes such as electrical conductivity have provided conflicting results ${ }^{8-10}$, and the issue of whether the transition zone contains abundant water remains highly controversial $^{11}$. Here we report X-ray diffraction, Raman and infrared spectroscopic data that provide, to our knowledge, the first evidence for the terrestrial occurrence of any higher-pressure polymorph of olivine: we find ringwoodite included in a diamond from Juína, Brazil. The water-rich nature of this inclusion, indicated by infrared absorption, along with the preservation of the ringwoodite, is direct evidence that, at least locally, the transition zone is hydrous, to about 1 weight per cent. The finding also indicates that some kimberlites must have their primary sources in this deep mantle region.

Samples of mantle-derived peridotites show that olivine $\left(\mathrm{Mg}_{2} \mathrm{SiO}_{4}\right)$ is the dominant phase in the Earth's shallow upper mantle, to a depth of $\sim 400 \mathrm{~km}$ (ref. 12). At greater depths, between approximately 410 and $660 \mathrm{~km}$, within the transition zone, the high-pressure olivine polymorphs wadsleyite and ringwoodite are thought to dominate mantle mineralogy owing to the fit of seismic discontinuity data to predictions from phase equilibria ${ }^{12,13}$. No unretrogressed samples of any highpressure olivine polymorph have been sampled from the mantle, and, hence, this inference is highly likely, but is unconfirmed by sampling. Sampling the transition zone is important because it is thought to be the main region of water storage in the solid Earth, sandwiched between relatively anhydrous shallow upper mantle and lower mantle $e^{4-7}$. The potential presence of significant water in this part of the Earth has been invoked to explain key aspects of global volcanism ${ }^{5}$ and has significant implications for the physical properties and rheology of the transition zone $e^{3,11,14}$. Finding confirmatory evidence of the presence of ringwoodite in Earth's mantle, and determining its water content, is an important step in understanding deep Earth processes.

The discovery of ultradeep diamonds, originating below the lithospheric mantle ${ }^{15-22}$, allows a unique window into the material constituting the Earth's transition zone. As such, these diamonds should provide the best opportunity for finding both wadsleyite and ringwoodite. Moreover, several studies have reported olivine that may have originated as a higher-pressure polymorph ${ }^{21-25}$.

In this study, we focused on diamonds from the Juína district of Mato Grosso, Brazil, in a search for ultrahigh-pressure inclusions. Alluvial deposits centred on tributaries East of the Rio Aripuanã, Juína District, contain abundant diamonds that originate in the Earth's transition zone and lower mantle $\mathrm{e}^{15-19,24,26}$.

Diamond JUc29 is a $0.09 \mathrm{~g}$, colourless/light-brown, irregular crystal (Extended Data Fig. 1) from deposits of the Rio Vinte e Um de Abril, downstream from kimberlite pipe Aripuanã-01. It exhibits a high degree of surface resorption, is moderately plastically deformed and its nitrogen content is below detection by infrared spectrometry; that is, the diamond is type IIa. These are all characteristics of most ultradeep diamonds from Juína ${ }^{18}$. A crystal of greenish appearance and $\sim 40 \mu \mathrm{m}$ in its maximum dimension was located optically in the diamond (Extended Data Fig. 1). Synchrotron X-ray tomography shows the inclusion to form part of a pair, with a Ca-rich and a Fe-bearing phase immediately adjacent (Extended Data Fig. 2). Single-crystal X-ray diffraction of the Fe-bearing phase revealed the main four diffraction peaks of ringwoodite, in their relative order of expected intensity ${ }^{4}$, that is, in descending order of intensity, the (113) plane at $2.44 \AA$, the (440) plane at $1.40 \AA$, the (220) plane at $2.81 \AA$ and the (115) plane at $1.51 \AA$ (Extended Data Fig. 3). The expected fifth peak at about $2.02 \AA$ was not found, being covered by the very intense diamond peak, which occurs at the same $d$ spacing (the single distance between two atomic lattice planes belonging to a family of infinite lattice planes all equidistant and parallel). The positions of these peaks (that is, the $d$ spacing) and, in particular, the precisely measured relative order of intensities, detected by chargecoupled device (CCD), confirm the identity of the inclusion as ringwoodite but do not allow an accurate compositional estimate.

Micro-Raman spectra of the inclusion (Fig. 1, grey traces) allowed ringwoodite to be identified by the two intense Raman bands that form a doublet corresponding to the asymmetric $\left(\mathrm{T}_{2 \mathrm{~g}}\right)$ and symmetric $\left(\mathrm{A}_{1 \mathrm{~g}}\right)$ stretching vibrations of $\mathrm{SiO}_{4}$ tetrahedra and which occur in the spectral regions $\sim 807$ and $860 \mathrm{~cm}^{-1}$, respectively. We refer to these bands as DB1 and DB2, respectively. The spacing of these two bands is 30\% wider than those present in olivine, and DB1 is displaced to significantly lower wavenumbers. Band DB1 in JUc29 is defined from peak fitting to be located between 807 and $809 \mathrm{~cm}^{-1}$, with DB2 between 854 and $860 \mathrm{~cm}^{-1}$. The increase in wavenumber of both DB1 and DB2 relative to the reference spectrum in Fig. 1 (red trace) and other synthetic ringwoodites is due largely to the influence of the compressive stress developed around the inclusion. This stress results from the difference in the volume expansion of the inclusion relative to the diamond that has helped to preserve the ringwoodite. All JUc29 Raman spectra show significant broadening of these $\mathrm{SiO}_{4}$ stretching vibrations. This broadening is probably due to increased disordering resulting from a tendency for ringwoodite to revert to olivine at lower pressure, and hampers the use of the doublet band separation in estimating the composition of the ringwoodite. Nevertheless, an estimate of the composition can be attempted, on the basis of the shift in DB1 in response to pressure and increasing Fe in the structure, which have opposite effects (see Methods

${ }^{1}$ Department of Earth and Atmospheric Sciences, 1-26 Earth Sciences Building, University of Alberta, Edmonton, Alberta T6G 2E3, Canada. ${ }^{2}$ Geoscience Institute - Mineralogy, Goethe University,

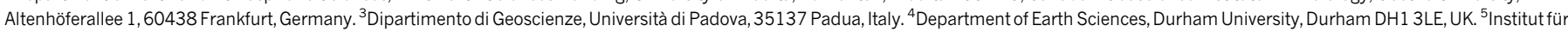

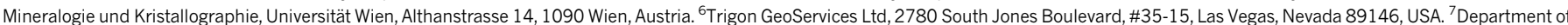
Analytical Chemistry, Ghent University, Krijgslaan 281 S12, B-9000 Ghent, Belgium. 


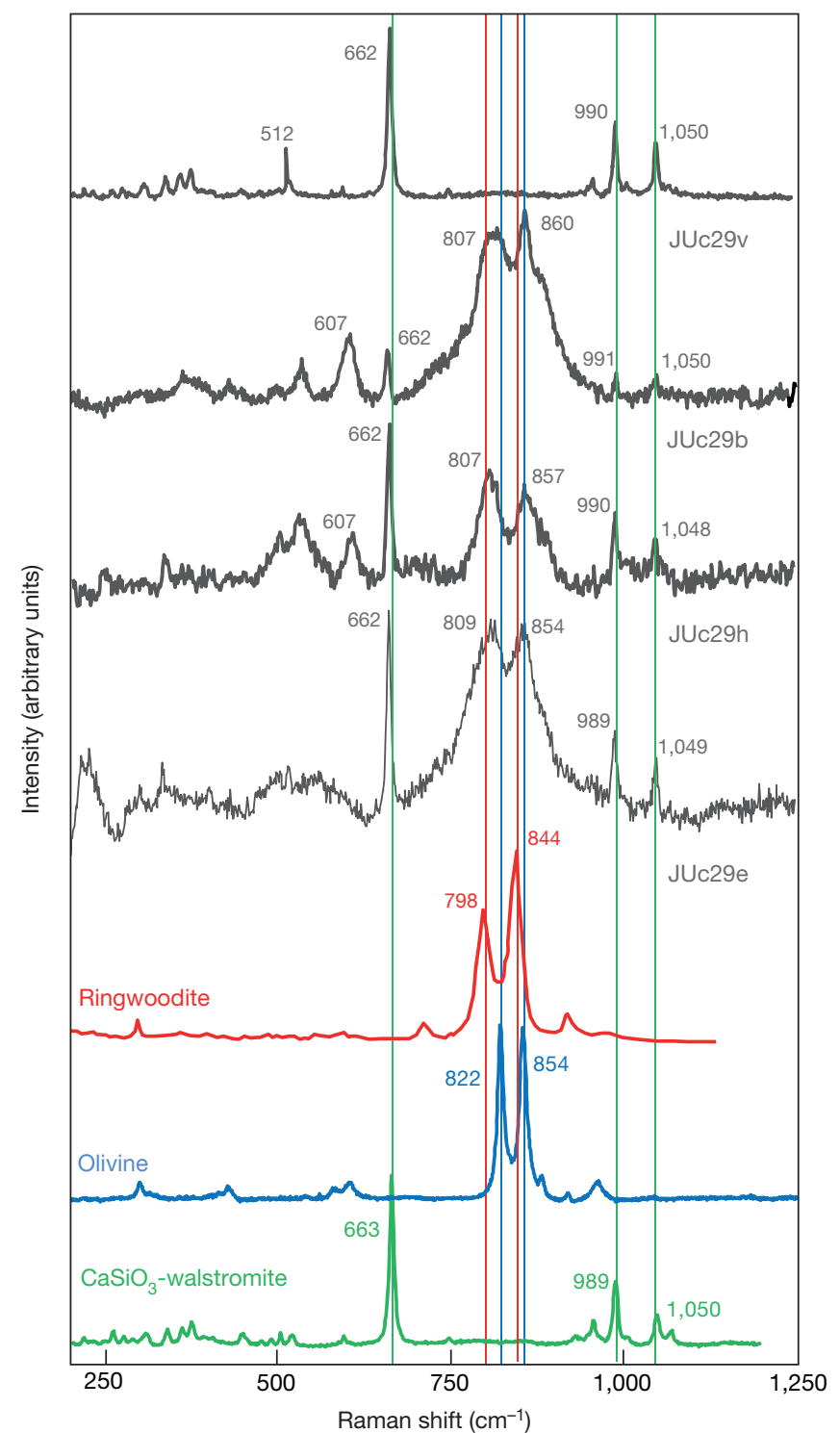

Figure 1 Raman spectra of ringwoodite and walstromite inclusions in Juína diamond JUc29. Raman spectra (unsmoothed, background-subtracted, in relative intensity units, stacked for clarity, shown in grey) for two-phase inclusion within JUc29 diamond, Juína. Spectra are complex, displaying $\mathrm{SiO}_{4}{ }^{-}$stretching modes for ringwoodite $\left([\mathrm{Mg}, \mathrm{Fe}] \mathrm{SiO}_{4}\right)$ that are broadened, probably by disordering induced by incipient retrogression, as well as the characteristic modes for Ca-walstromite $\left(\mathrm{CaSiO}_{3}\right)$. Reference spectra for olivine (blue), ringwoodite (red) and $\mathrm{CaSiO}_{3}$-walstromite (green) are from refs 20, 33 .

section on Raman spectroscopy). The compressive stress imposed on the inclusion was estimated by measuring the Raman shift of the main diamond band in the immediately adjacent diamond $\left(1,337 \mathrm{~cm}^{-1}\right)$, which yields internal pressures of between 1.7 and $2.3 \mathrm{GPa}$ depending on the pressure calibration of the Raman shift used (see Methods as above). Our estimate for the resulting phase composition yields a $\mathrm{Mg}$ number, $\mathrm{Mg} \#=100 \mathrm{Mg} /(\mathrm{Mg}+\mathrm{Fe})$, of $75_{-21}^{+24}$, where the uncertainty is dominated by the uncertainty in the confining pressure, the exact position of DB1 and the calibration of DB1's position with composition (see Methods as above). Although the compositional uncertainty is large, the presence of significant $\mathrm{Fe}$ in the structure is consistent with the confocal X-ray fluorescence data (Extended Data Fig. 2).

Additional Raman-active bands at 662,990 and $1,050 \mathrm{~cm}^{-1}$ are present in the JUc29 spectra and can be attributed to the presence of $\mathrm{CaSiO}_{3}$-walstromite (Fig. 1) adjacent to ringwoodite. Spectrum JUc29v sampled only the Ca-rich phase and is spectrally very similar to reference $\mathrm{CaSiO}_{3}$-walstromite (Fig. 1, green trace).
Fourier transform infrared (FTIR) spectra for the inclusion reveal a pronounced $\mathrm{OH}^{-}$stretching vibration with the band centre between 3,150 and $3,200 \mathrm{~cm}^{-1}$ (Fig. 2). The broad band at $3,150 \mathrm{~cm}^{-1}$ and that at $3,680 \mathrm{~cm}^{-1}$ correspond to $\mathrm{OH}^{-}$stretching modes reported in synthetic hydrous ringwoodite $\mathrm{e}^{27-31}$. The correspondence between the general form of the JUc29 FTIR spectra and that of synthetic hydrous ringwoodite ${ }^{4,27-31}$, together with the location of the main $\mathrm{OH}^{-}$stretching band at considerably lower wavenumber than either hydrous olivine or wadsleyite strongly support the identification of our inclusion as not only ringwoodite, but ringwoodite containing significant water. The location of the main $\mathrm{OH}^{-}$band at between 3,160 and $3,180 \mathrm{~cm}^{-1}$ seems to support a composition between Mg\# 60 and Mg\# 100 (see Methods section on FTIR spectroscopy), and is hence consistent with the Raman estimate.

The phase assemblage presented by the inclusion pair can be used to constrain their likely depth of origin. Two scenarios are possible, indicative of different depths of mantle sampling. Ca-walstromite is stable, along a mantle geotherm, at or below $10 \mathrm{GPa}$ (refs 20,26), where ringwoodite with $\mathrm{Mg \#} \sim 75$ must coexist with olivine in a two-phase loop ${ }^{12}$. Although the peak broadening of the main doublet in some of the ringwoodite Raman spectra (for example JUc29v; Fig. 1) indicates the possibility of partial retrogression to olivine in parts of the crystal, there is no indication of a highly crystalline olivine phase from the X-ray measurement. Hence, we interpret this phenomenon as disorder induced during the incipient breakdown of ringwoodite to olivine. Given this, the most likely interpretation of this two-phase assemblage is that it represents a partly retrogressed portion of a somewhat Fe-rich peridotitic mantle, in which hydrous ringwoodite and former $\mathrm{CaSiO}_{3}-$ perovskite coexisted above $15 \mathrm{GPa}^{12}$, that is, in the transition zone, probably with majorite garnet. The ringwoodite has largely avoided retrogression, whereas the $\mathrm{CaSiO}_{3}$-perovskite precursor reverted to Cawalstromite. The slightly more Fe-rich composition of the ringwoodite may arise by reaction between the peridotitic and basaltic portions of a subducted slab $^{26}$ and may not be indicative of the bulk of the transition zone because of the resulting broadening of the $410-\mathrm{km}$ seismic discontinuity that would be seen at such Fe-rich compositions ${ }^{12}$.

It is important to constrain the amount of water in the ringwoodite inclusion because this has implications for the water content of the transition zone. From experiments, ringwoodite may incorporate up to $2.5 \mathrm{wt} \% \mathrm{H}_{2} \mathrm{O}$ under transition-zone conditions $s^{2,4,30,31}$. The difficulties in constraining sample thickness during FTIR measurement, especially in determining whether the beam was sampling part of the Ca-walstromite inclusion, plus any spectral absorption by the rather impure diamond host, make the estimation of the ringwoodite water content subject to large uncertainty. The main $\mathrm{OH}^{-}$stretching band at $\sim 3,150 \mathrm{~cm}^{-1}$ in hydrous ringwoodite becomes more pronounced with increasing $\mathrm{H}_{2} \mathrm{O}$ content, up to $\sim 0.8 \mathrm{wt} \% \mathrm{H}_{2} \mathrm{O}$ (ref. 4; Fig. 2). The JUc29 spectra show strong $\mathrm{OH}^{-}$absorption, clearly indicative of significant $\mathrm{H}_{2} \mathrm{O}$ content, and are consistent with a minimum estimate between 1.4 and $1.5 \mathrm{wt} \% \mathrm{H}_{2} \mathrm{O}$, derived by integrating the spectra in Fig. 2 (see Methods section on FTIR spectroscopy). Although the uncertainty in these estimates may be as large as $50 \%$, we note that in synthetic ringwoodites containing $2 \mathrm{wt} \% \mathrm{H}_{2} \mathrm{O}$ or more, the satellite $\mathrm{OH}^{-}$stretching mode at $3,645-3,680 \mathrm{~cm}^{-1}$ transforms from a broad shoulder to a sharply defined vibrational band ${ }^{30}$. This stretching mode is well defined in the JUc29 inclusion, supporting our calculated water concentration as a minimum estimate.

Two main scenarios arise from the water-rich nature of the ringwoodite inclusion coming from transition-zone depths. In one, water within the ringwoodite reflects inheritance from a hydrous, diamondforming fluid, from which the inclusion grew as a syngenetic phase. In this model, the hydrous fluid must originate locally, from the transition zone, because there is no evidence that the lower mantle contains a significant amount of water. Alternatively, the ringwoodite is 'protogenetic', that is, it was present before encapsulation by the diamond and its water content reflects that of the ambient transition zone. Both 


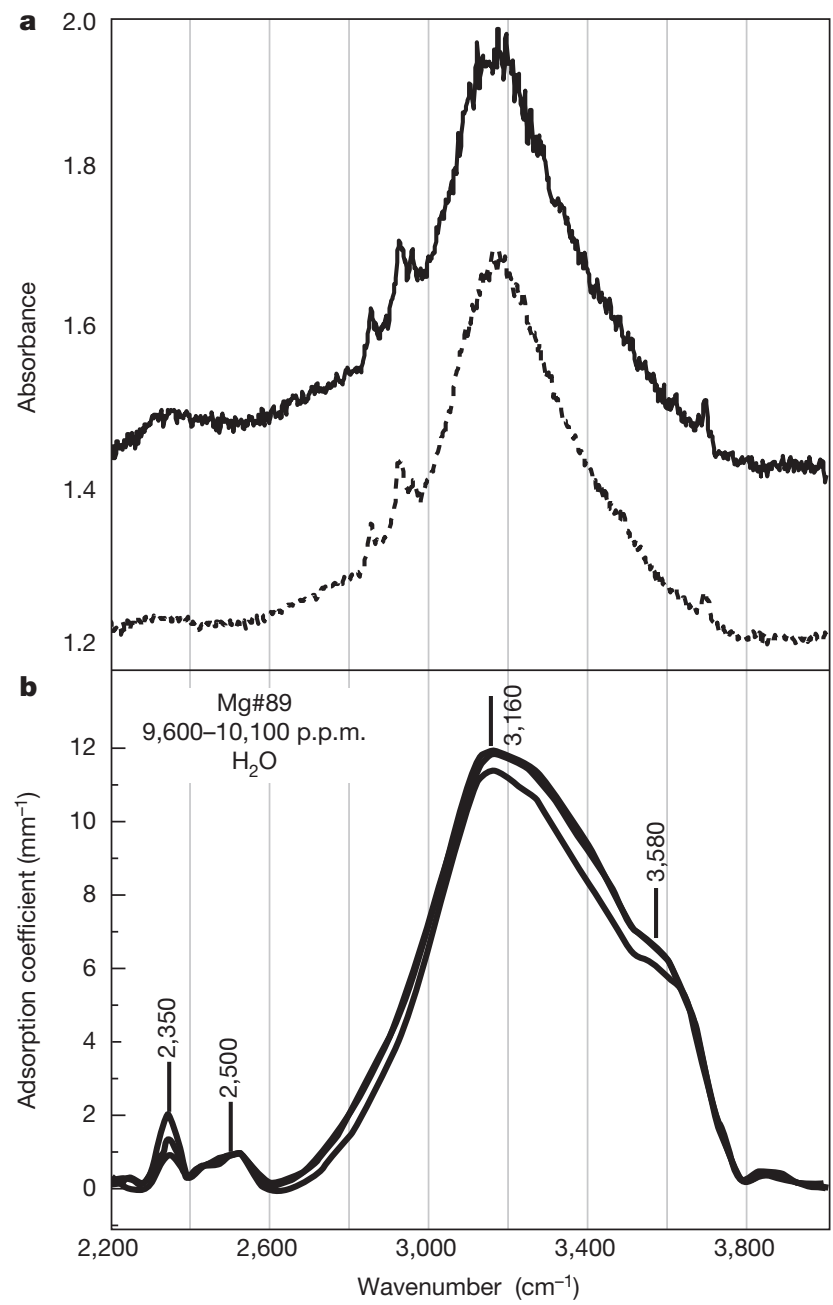

Figure 2 FTIR spectra of ringwoodite inclusion in Juína diamond JUc29. a, Unpolarized FTIR spectra for ringwoodite inclusion in diamond JUc29 between 2,200 and $3,900 \mathrm{~cm}^{-1}$. The two spectra were measured at $\sim 90^{\circ}$ degrees to each other and are unsmoothed, but were corrected for a background that includes the intrinsic response of the host diamond. Water contents calculated by integration of these two spectra are between 1.4 and $1.5 \mathrm{wt} \%$ (see Methods section on FTIR). b, Reference spectra for hydrous Fe-bearing ringwoodite (Mg\# 89) containing $\sim 1 \mathrm{wt} \% \mathrm{H}_{2} \mathrm{O}$ (ref. 27).

models implicate a transition zone that is at least locally water-rich. It is interesting to explore the protogenetic option further to see what bounds would be placed on the bulk transition-zone water content in the light of geophysical observations.

Using a conservative estimate of the $\mathrm{H}_{2} \mathrm{O}$ content of JUc29 ringwoodite, of $1.4 \mathrm{wt} \%$, combined with mineral mode estimates ${ }^{12}$ and water solubilities for majorite and Ca-perovskite ${ }^{6}$, results in a bulk water content of $\sim 1.0 \mathrm{wt} \%$ for the transition zone sampled by our diamond. This value is broadly aligned with the highest transition-zone water contents estimated from electromagnetic data ${ }^{11,32}$. Other studies of ultradeep diamonds have indicated the transition zone could contain stagnated subducted slabs ${ }^{17-26}$ that may transport water to this mantle region. The presence of hydrous ringwoodite in a diamond from transition-zone depths supports the view that high fluid activity, notably that of water, has a key role in the genesis of ultradeep diamond ${ }^{26}$ and is consistent with the proposal of regionally localized 'wet-spots' in the transition zone $^{32}$ that may host thin melt layers above the $410-\mathrm{km}$ discontinuity ${ }^{7}$. Our observations provide clear support for experimental measurements ${ }^{27}$ showing that the $P$ - and $S$-wave velocities of the lower transition zone are consistent with a hydrated ringwoodite-rich composition. The preservation of ringwoodite within diamond also provides a strong indication that some kimberlites must come from at least transitionzone depths.

\section{METHODS SUMMARY}

Full descriptions of all analytical methods and calculations of the compositional estimates are provided in Methods. Micro-X-ray fluorescence measurements were performed at beamline L of the DORIS-III synchrotron facility at HASYLAB (DESY, Germany). Measurements were made using confocal detection of an internal microscopic volume element of approximately $22 \mu \mathrm{m} \times 22 \mu \mathrm{m} \times 16 \mu \mathrm{m}$ (full-width at half-maximum). Single-crystal X-ray diffraction was performed at the Dipartimento di Geoscienze, Università di Padova, Italy using a CCD detector coupled to a STOE STADI IV single-crystal diffractometer, via monochromatized $\mathrm{Mo}_{\mathrm{K} \alpha}$ radiation $(\lambda=0.71073 \AA)$, working at $50 \mathrm{kV}$ and $40 \mathrm{~mA}$ and with an exposure time of $60 \mathrm{~s}$. We obtained the main four diffraction peaks of ringwoodite (RINGW: Extended Data Fig. 3), that is, the planes (113) at $2.44 \AA$, (440) at $1.40 \AA,(220)$ at $2.81 \AA$ and (115) at $1.51 \AA$, in the expected order of relative intensity. Raman spectroscopy was carried out at the Geoscience Institute, Goethe University, Germany, using a Renishaw micro-Raman spectrometer (RM-1000) equipped with a Leica DMLM optical microscope and CCD detector. Spectra were excited with the HeNe $632.8-\mathrm{nm}$ line $(\max 50 \mathrm{~mW})$. The wavenumber accuracy was $0.5 \mathrm{~cm}^{-1}$ and the spectral resolution was $\sim 1 \mathrm{~cm}^{-1}$. The lateral resolution at the sampling depth was several micrometres and the depth resolution was several tens of micrometres. Details of the calculation of the ringwoodite composition from the Raman spectra are given in Methods. FTIR spectra were obtained with a Nicolet Continu $\mu \mathrm{m}$ infrared microscope attached to a Thermo Nicolet Nexus 470 FTIR Spectrometer at the De Beers Laboratory of Diamond Research, University of Alberta, Canada. All measurements were performed in transmitted mode, with an unpolarized beam of aperture size $70 \mu \mathrm{m}$. Two hundred scans were acquired with a spectral resolution $4 \mathrm{~cm}^{-1}$. Details of the calculation of water content from the spectra are given in Methods.

Online Content Any additional Methods, Extended Data display items and Source Data are available in the online version of the paper; references unique to these sections appear only in the online paper.

\section{Received 16 September 2013; accepted 21 January 2014.}

1. Smyth, J. R. $\beta-\mathrm{Mg}_{2} \mathrm{SiO}_{4}$ : a potential host for water in the mantle? Am. Mineral. $\mathbf{7 2}$ 1051-1055 (1987)

2. Chen, J., Inoue, T., Yurimoto, H. \& Weidner, D. J. Effect of water on olivine- wadsleyite phase boundary in the (Mg,Fe $)_{2} \mathrm{SiO}_{4}$ system. J. Geophys. Res. Lett. 29, 1875 (2002).

3. Kohlstedt, D. L., Keppler, H. \& Rubie, D. C. Solubility of water in the $\alpha, \beta$ and $\gamma$ phases of $(\mathrm{Mg}, \mathrm{Fe})_{2} \mathrm{SiO}_{4}$. Contrib. Mineral. Petrol. 123, 345-357 (1996).

4. Smyth, J. R. et al. Structural systematics of hydrous ringwoodite and water in Earth's interior. Am. Mineral. 88, 1402-1407 (2003).

5. Bercovici, D. \& Karato, S. Whole-mantle convection and the transition zone water filter. Nature 425, 39-44 (2003)

6. Bolfan-Casanova, N. Water in the Earth's mantle. Mineral. Mag. 69, 229-258 (2005).

7. Hirschmann, M. Water, melting and the deep Earth $\mathrm{H}_{2} \mathrm{O}$ cycle. Annu. Rev. Earth Planet. Sci. 34, 629-653 (2006).

8. Huang, X., Xu, Y. \& Karato, S. Water content in the transition zone from electrical conductivity of wadsleyite and ringwoodite. Nature $\mathbf{4 3 4}, \mathbf{7 4 6 - 7 4 9}$ (2005).

9. Xu, Y., Shankland, T. J. \& Rubie, D. C. Electrical conductivity of olivine, wadsleyite and ringwoodite under upper-mantle conditions. Science 280, 1415-1418 (1998).

10. Yoshino, T., Manthilake, G., Matsuzaki, T. \& Katsura, T. Dry mantle transition zone inferred from the conductivity of wadsleyite and ringwoodite. Nature $\mathbf{4 5 1}$ 326-329 (2008).

11. Khan, A. \& Shankland, T. J. A geological perspective on mantle water content and melting: inverting electromagnetic sounding data using laboratory-based electrical conductivity profiles. Earth Planet. Sci. Lett. 317-318, 27-43 (2012).

12. Agee, C. B. in Ultrahigh-Pressure Mineralogy (ed. Hemley, R. J.) 165-203 (Rev. Mineral. 37, Mineralogical Society of America, 1998).

13. Ringwood, A. E. \& Major, A. The system $\mathrm{Mg}_{2} \mathrm{SiO}_{4}-\mathrm{Fe}_{2} \mathrm{SiO}_{4}$ at high pressures and temperatures. Phys. Earth Planet. Inter. 3, 89-108 (1970).

14. Ye, Y. et al. Compressibility and thermal expansion of hydrous ringwoodite with $2.5 \mathrm{wt} \% \mathrm{H}_{2} \mathrm{O}$. Am. Mineral. 97, 573-582 (2012).

15. Harris, J. W., Hutchison, M. T., Hursthouse, M., Light, M. \& Harte, B. A new tetragonal silicate mineral occurring as inclusions in lower mantle diamonds. Nature $\mathbf{3 8 7}$, 486-488 (1997).

16. Harte, B. \& Harris, J. W. Lower mantle associations preserved in diamonds Mineral. Mag. 58A, 384-385 (1994).

17. Harte, B., Harris, J. W., Hutchison, M. T., Watt, G. R. \& Wilding, M. C. in Mantle Petrology: Field Observations and High Pressure Experimentation Vol. 6 (eds Fei, Y. \& Bertka, C. M.) 125-153 (Geochem. Soc. Spec. Publ., The Geochemical Society, 1999). 
18. Hutchison, M. T., Cartigny, P. \& Harris, J. W. in Proc. 7th Int. Kimberlite Conf. (eds Gurney, J. J., Gurney, J. L., Pascoe, M. D. \& Richardson, S. H.) 372-382 (Red Roof Design, 1999).

19. Hutchison, M. T., Hursthouse, M. B. \& Light, M. E. Mineral inclusions in diamonds: associations and chemical distinctions around the $670-\mathrm{km}$ discontinuity. Contrib. Mineral. Petrol. 142, 119-126 (2001).

20. Brenker, F. et al. Detection of a Ca-rich lithology in the deep (>300 km) convecting mantle. Earth Planet. Sci. Lett. 236, 579-587 (2005).

21. Stachel, T., Brey, G. P. \& Harris, J. W. Inclusions in sublithospheric diamonds: glimpses of deep Earth. Elements 1, 73-78 (2005).

22. Stachel, T., Harris, J. W., Brey, G. P.\& Joswig, W. Kankan diamonds (Guinea) II: lower mantle inclusion paragenesis. Contrib. Mineral. Petrol. 140, 16-27 (2000).

23. Bulanova, G. et al. Mineral inclusions in sublithospheric diamonds from Collier 4 kimberlite pipe, Juina, Brazil: subducted protoliths, carbonated melts and primary kimberlite magmatism. Contrib. Mineral. Petrol. 160, 489-510 (2010).

24. Hayman, P. C., Kopylova, M. G. \& Kaminsky, F. V. Lower mantle diamonds from Rio Soriso (Juina area, Mato Grosso, Brazil). Contrib. Mineral. Petrol. 149, 430-445 (2005).

25. Tappert, R., Stachel, T., Harris, J. W., Shimizu, N. \& Brey, G. P. Mineral inclusions in diamonds from the Panda kimberlite, Slave Province, Canada. Eur. J. Mineral. 17 423-440 (2005).

26. Harte, B. Diamond formation in the deep mantle: the record of mineral inclusions and their distribution in relation to mantle dehydration zones. Mineral. Mag. 74, 189-215 (2010).

27. Jacobsen, S. D., Smyth, J. R., Spetzler, H., Holl, C. M. \& Frost, D. J. Sound velocities and elastic constants of iron-bearing hydrous ringwoodite. Phys. Earth Planet. Inter. 143-144, 47-56 (2004).

28. Blanchard, M., Balan, E. \& Wright, K. Incorporation of water in iron-free ringwoodite: a first principles study. Am. Mineral. 94, 83-89 (2009).

29. Bolfan-Casanova, N., Keppler, H. \& Rubie, D. C. Water partitioning between nominally anhydrous minerals in the $\mathrm{MgO}-\mathrm{SiO}_{2}-\mathrm{H}_{2} \mathrm{O}$ system up to $24 \mathrm{GPa}$ : implications for the distribution of water in the Earth's mantle. Earth Planet. Sci. Lett. 182, 209-221 (2000).
30. Keppler, H. \& Bolfan-Casanova, N. in Water in Nominally Anhydrous Minerals (eds Keppler, H. \& Smyth, J. R.) 193-230 (Rev. Mineral. 62, Mineralogical Society of America, 2006).

31. Kleppe, A. K., Jephcoat, A. P. \& Smyth, J. R. Raman spectroscopic study of hydrous $\gamma-\mathrm{Mg}_{2} \mathrm{SiO}_{4}$ to $56.5 \mathrm{GPa}$. Phys. Chem. Miner. 29, 473-476 (2002).

32. Kelbert, A., Schultz, A. \& Egbert, G. Global electromagnetic induction constraints on transition-zone water content variations. Nature 460, 1003-1006 (2009).

33. Chen, M., El Goresy, A. \& Gillet, P. Ringwoodite lamellae in olivine: clues to olivineringwoodite phase transition mechanisms in shocked meteorites and subducting slabs. Proc. Natl Acad. Sci. USA 101, 15033-15037 (2004).

Acknowledgements D.G.P. acknowledges CERC funding for this study. F.N. is supported by ERC Starting Grant 307322. Support from the Alfred P. Sloan Foundation's Deep Carbon Observatory project created this research partnership. We thank T. Stachel for comments on the manuscript plus access to the FTIR instrument at the De Beers Laboratory of Diamond Research at the University of Alberta, and we thank J. Harris for discussions. Sample JUc29 was provided by Trigon GeoServices Ltd.

Author Contributions D.G.P. had the idea for the study, wrote the manuscript and helped perform the Raman and FTIR measurements. F.E.B. performed the Raman measurements and ion-milling and made compositional estimates. F.N. performed X-ray measurements. J.M. and L.N. first identified the inclusion as ringwoodite. M.T.H. selected the diamond for this study and assisted with manuscript preparation and geological background. S.M. performed the FTIR measurements and the water content estimate. K.M. assisted with manuscript preparation. G.S., S.S., B.V. and L.V. performed the synchrotron X-ray mapping measurements.

Author Information Reprints and permissions information is available at www.nature.com/reprints. The authors declare no competing financial interests. Readers are welcome to comment on the online version of the paper. Correspondence and requests for materials should be addressed to D.G.P. (gdpearso@ualberta.ca). 


\section{METHODS}

Micro-X-ray fluorescence. Micro-X-ray fluorescence ( $\mu \mathrm{XRF})$ measurements were performed at beamline L of the DORIS-III synchrotron facility at HASYLAB (DESY, Germany). Measurements were made using a confocal detection scheme that enables direct non-destructive extraction of three-dimensional elemental/chemicalstate information from an internal microscopic volume element of approximately $22 \mu \mathrm{m} \times 22 \mu \mathrm{m} \times 16 \mu \mathrm{m}$ (full-width at half-maximum). The confocal detection mode ensures that the measurements are insensitive to surface features, recording information only from the depth of the inclusion. Fe and Ca confocal $\mu$ XRF measurements were recorded with an excitation energy of 7,200 eV using methods described in full elsewhere ${ }^{34,35}$, and were combined to produce the three-dimensiona confocal micro-X-Ray fluorescence view of two-phase inclusion shown in Extended Data Fig. 2. With this measurement arrangement, Mg could not be determined and, hence, we could not constrain the Fo content of the inclusion by these means. Single-crystal X-ray diffraction. Single-crystal X-ray diffraction was performed at the Dipartimento di Geoscienze, Università di Padova, Italy. A CCD detector (Oxford Diffraction) was used, coupled to a STOE STADI IV single-crystal diffractometer, using monochromatized $\mathrm{Mo}_{\mathrm{K} \alpha}$ radiation $(\lambda=0.71073 \AA)$, working a $50 \mathrm{kV}$ and $40 \mathrm{~mA}$ and with an exposure time of $60 \mathrm{~s}$. We obtained the main four diffraction peaks of ringwoodite (RINGW: Extended Data Fig. 3), that is, the planes (113) at $2.44 \AA,(440)$ at $1.40 \AA,(220)$ at $2.81 \AA$ and (115) at $1.51 \AA$, in the expected order of relative intensity ${ }^{4}$. These data are not significantly affected by confining pressure because the diamond was ion-milled so that the inclusion was almost at the diamond surface. The very small size of the inclusion, combined with the inability of CCD devices to provide accurate and precise $d$ spacings, means that the diffraction data can only be used for identification of ringwoodite and cannot be used as an indication of composition. The very similar $d$ spacings reported for pure $\mathrm{Mg}_{2} \mathrm{SiO}_{4}$ (ref. 4) and $\mathrm{Fe}_{2} \mathrm{SiO}_{4}$ (ref. 36) spinels, that is, the (113) plane at $2.43 \AA$ ( $\mathrm{Mg}$ ) versus $2.48 \AA$ (Fe), (440) at $1.42 \AA$ versus $1.46 \AA$, (220) at $2.85 \AA$ versus $2.91 \AA$, and (115) at $1.55 \AA$ versus $1.58 \AA$, make compositional distinction very challenging even under optimal conditions.

The diffraction spots identifying ringwoodite in the CCD image cannot be assigned to olivine or wadsleyite. Mg-rich olivine has the following sequence of main peaks (with intensity given relative to that of the most intense peak): $2.46 \AA$ (100\%), $2.51 \AA$ ( $80 \%), 1.75 \AA$ (68\%), $3.88 \AA$ (64\%), $2.76 \AA$ (63\%), $2.27 \AA$ (44), $1.48 \AA$ (44\%), $1.49 \AA$ (31\%), $5.09 \AA$ (22\%) (see, for example, ref. 37). In wadsleyite, the main peaks are $1.44 \AA$ (100\%), $2.44 \AA$ (91\%), $2.02 \AA$ (75\%), $2.62 \AA$ (57\%), $2.68 \AA$ (48\%) and $3.21 \AA$ (43\%) (ref. 38). For olivine, none of the critical, high-intensity peaks at $1.75,3.88$ and $2.76 \AA$ was observed in our measurement, and these peaks do not overlap with those of diamond. For wadsleyite, none of the $1.44,2.02,2.62$, 2.68 or $3.21 \AA$ high-intensity peaks was observed. Hence, the mineral phase cannot be anything other than ringwoodite.

To avoid the risk of thermal shock breaking the diamond, or acid ingress to any unseen cracks attacking the inclusion, we chose not to clean the host diamond with acid. This results in a total sample transmission technique such as X-ray diffraction detecting surface features not seen by the confocal or nearly confocal methods. Hence, in addition to the ringwoodite diffraction peaks, the main peak of quartz which occurs in resorption pits on the sample surface and is not included within the diamond, is evident. The prominent diffraction rings result from very fine clay minerals present on the surface of the diamond. At least one diffraction peak, at $3.03 \AA$, probably results from the $\mathrm{CaSiO}_{3}$-walstromite inclusion.

Raman spectroscopy and compositional estimate. Raman spectroscopy was carried out at the Geoscience Institute, Goethe University, Frankfurt, using a Renishaw micro-Raman spectrometer (RM-1000) equipped with a Leica DMLM optical microscope and CCD detector. Spectra were excited with the $\mathrm{He}-\mathrm{Ne} 632.8$ $\mathrm{nm}$ line $(\max 50 \mathrm{~mW})$. The wavenumber accuracy was $0.5 \mathrm{~cm}^{-1}$ and the spectral resolution was $\sim 1 \mathrm{~cm}^{-1}$. The lateral resolution at the sampling depth was several micrometres and the depth resolution was several tens of micrometres. A detailed description of the technique is given in refs 34,39 .

The Raman spectra for the inclusion pair measured within JUc29, before ionmilling (Fig. 1) are complex. The doublet between 800 and $850 \mathrm{~cm}^{-1}$ is characteristic, both in terms of band position and band separation, of ringwoodite. No other silicate mineral has a doublet response with these characteristics. In contrast to the $\mathrm{X}$-ray diffraction data (see previous section), acquired after the diamond above the inclusion was thinned by ion-milling, Raman spectroscopy was undertaken before any laboratory modification of the diamond host. Consequently, the position of both bands of the doublet (referred to as DB1, for low wavenumber, and DB2, for high wavenumber, in our main text) are shifted from those of, for example, pure $\mathrm{Mg}$-endmember ringwoodite at ambient pressure ${ }^{33}$, due to the compounding effects of a significant compressive stress $(\sim 2.3 \mathrm{GPa}$; see below) and the presence of $\mathrm{Fe}$ in the structure such that DB2 is at, or close to, the olivine position (main text and Fig. 1). The much lower characteristic wavenumber of DB1 precludes any chance that the spectra can be those of olivine. Band broadening is clearly present and probably results from disordering due to incipient retrogression to lower-pressure polymorphs.

The shift of Raman bands to higher wavenumber with increasing pressure is well known, especially in diamond ${ }^{40,41}$, and has been experimentally calibrated in ringwoodite $^{42,43}$. Regression of the data sets of refs 42,43 yields slopes equivalent to changes in the position of DB1 of 4.3 and $5.9 \mathrm{~cm}^{-1}$ per gigapascal pressure increase, respectively, with a regression coefficient of determination of 1 in both cases. For the compositional estimate below, we chose the pressure shift of DB1's position from ref. 42 because this was measured for Fe-bearing ringwoodite $\left(\mathrm{Fo}_{89}\right)$ The uncertainty generated by instead using the calibration from ref. 43 is factored into our total uncertainty budget.

Less well characterized, until recently, has been the Raman band shift with changing ringwoodite composition. The most significant compositional variations in ringwoodite arise from the substitution of $\mathrm{Fe}^{2+}$ for $\mathrm{Mg}^{2+}$, with full solidsolution quantified by the $\mathrm{Mg} \#(100 \mathrm{Mg} /(\mathrm{Mg}+\mathrm{Fe}))$. A calibration of the shift of position of both DB1 and DB2 over the range Mg\# 72-19 has been made using a shocked L5 chondrite meteorite ${ }^{44}$. There the Raman band positions were calibrated to compositional data determined by electron microprobe for 28 highquality measurements. The resulting form of the equation, expressed in Fe\# units $(100 \mathrm{Fe} /(\mathrm{Mg}+\mathrm{Fe}))$, is

$$
\mathrm{Fe} \#=y_{i}+a_{i} x_{i}+b_{i} x_{i}^{2}
$$

where $i$ refers to DB1, $x_{i}$ refers to the band position, $y_{i}$ refers to the intercept, and $a_{i}$ and $b_{i}$ are coefficients given as -12.32257 and 0.01291 , respectively ${ }^{40}$. Because there are fewer points and more scatter at high $\mathrm{Mg \# ,} \mathrm{it} \mathrm{is} \mathrm{possible} \mathrm{that} \mathrm{at} \mathrm{the} \mathrm{Mg}$ rich, Fe-poor end of the calibration the inaccuracy may be up to $7 \%$. The overall calibration uncertainty is stated as $5 \%$, and this is propagated as an error in the total uncertainty estimate that we provide in the main text when estimating the ringwoodite composition.

For JUc29 ringwoodite, the compositional estimate from the Raman data was made using a DB1 position of $808 \mathrm{~cm}^{-1}$, intermediate between the two measured values of 807 and $809 \mathrm{~cm}^{-1}$ (Fig. 1). We propagate the effect of this uncertainty in the exact band position into the uncertainty budget. The data are pressurecorrected to a confining pressure of $2.3 \mathrm{GPa}$ using the shift of the first-order Raman band, measured at $1,337 \mathrm{~cm}^{-1}$ for diamond adjacent to JUc29 ringwoodite. We use the $+2.2 \mathrm{~cm}^{-1} \mathrm{GPa}^{-1}$ shift along [001] from ref. 40, yielding a surrounding compressive stress of $2.3 \mathrm{GPa}$. Using a non-directional calibration ${ }^{41}$ yields $1.7 \mathrm{GPa}$. The uncertainty arising from this difference is propagated into our total stated uncertainty budget. The resulting composition and uncertainty estimate of $\mathrm{Mg} \# 75_{-21}^{+24}$ is imprecise and can only be viewed as a first-order estimate of the composition of the ringwoodite included within JUc29. Nevertheless, its relatively Fe-rich nature, compared with average mantle olivine, Mg\# 89-91, is consistent with the $\mu$ XRF mapping (Extended Data Fig. 2). We note further that a composition on the Mgrich side of the $\mathrm{Mg}-\mathrm{Fe}$ solid solution is consistent with the location of the FTIR $\mathrm{OH}^{-}$absorption band in JUc29 between 3,160 and 3,180 $\mathrm{cm}^{-1}$, compared with the systematic shift in the main FTIR OH peak seen in fig. $1 \mathrm{~b}$ of ref. 45 . The location of the JUc29 OH bands are bracketed by the $3,120 \mathrm{~cm}^{-1}$ band at $\mathrm{Mg \#} 100$ and the $3,244 \mathrm{~cm}^{-1}$ band at $\mathrm{Mg} \# 60$.

Despite direct evidence from infrared absorption (below) of the presence of significant $\mathrm{OH}^{-}$, we did not observe any evidence in the Raman spectra of the $\mathrm{OH}^{-}$stretching vibrations expected to occur in the spectral range $3,100-3,700 \mathrm{~cm}^{-1}$, as reported in endmember $\mathrm{Mg}$-ringwoodite ${ }^{43}$. The lack of Raman response in this region for hydrous Fe-bearing ringwoodite has also been reported in experimental run products ${ }^{42}$ and is not surprising because the observed bands are weak, even in large crystals not surrounded by diamond. In addition, the observation of weak and broad $\mathrm{OH}^{-}$stretching bands would be made less likely because, as in ref. 42, we used a low laser power for our Raman measurements, to avoid thermal instability. FTIR spectroscopy. FTIR spectra were obtained with a Nicolet Continu $\mathrm{m}$ infrared microscope attached to a Thermo Nicolet Nexus 470 FTIR spectrometer at the De Beers Laboratory of Diamond Research, University of Alberta, Canada, following methods described in detail elsewhere ${ }^{46}$. During analysis, the infrared microscope and bench were continuously flushed with dried air to eliminate spectral noise at $3,600 \mathrm{~cm}^{-1}$ caused by water vapour in air. All measurements were performed in transmitted mode, with an unpolarized beam of aperture size of $70 \mu \mathrm{m}$, and 200 scans were acquired with a spectral resolution of $4 \mathrm{~cm}^{-1}$. Fol lowing spectral acquisition, the intrinsic background of the diamond host was measured and subtracted. Two identical spectra were obtained at $\sim 90^{\circ}$ degrees orientation to each other. Measurements taken in the diamond host away from the ringwoodite inclusion yielded no signal over the diamond background in the spectral range $3,800-2,600 \mathrm{~cm}^{-1}$. The lack of signal from the $\mathrm{SiO}_{4}$ overtones at lower wavenumbers seems to be due to either absorption by the diamond structure 
or masking by the intrinsic diamond bands, or both, and, hence, may have been subtracted out.

We calculated the water content of the ringwoodite from the two spectra presented in Fig. 2 using the method of ref. 45. The basis of this method applies the Beer-Lambert law in the form

$$
A_{i \text { tot }}=\varepsilon_{i} \mathrm{Ct}
$$

where $A_{i \text { tot }}$ is the integrated absorbance $\left(A_{i}\right)$ multiplied by 3 (as suggested in ref. 47), $\varepsilon_{i}$ is the extinction coefficient in $1\left(\mathrm{~mol} \mathrm{H}_{2} \mathrm{O}\right)^{-1} \mathrm{~cm}^{-2}, C$ is the concentration in $\mathrm{mol} \mathrm{H}_{2} \mathrm{Ol}^{-1}$ and $t$ is the sample thickness, which is normalized to $1 \mathrm{~cm}$. The concentration is thus proportional to integrated absorbency and negatively correlates with extinction coefficient, that is, lower $\varepsilon_{i}$ in this scheme corresponds to a higher water concentration for a given infrared $\mathrm{OH}$ intensity.

The conversion to p.p.m. $\mathrm{H}_{2} \mathrm{O}$ is achieved via

$$
C_{\text {(p.p.m. } \left.\mathrm{H}_{2} \mathrm{O}\right)}=\left(3 A_{i \text { tot }} / \varepsilon_{i} / t\right) K
$$

where $K$ is the conversion factor from $\mathrm{mol} \mathrm{H}_{2} \mathrm{Ol}^{-1}$ to p.p.m. $\mathrm{H}_{2} \mathrm{O} ; A_{i \text { tot }}$ is the integrated $\mathrm{OH}$ absorption normalized to $1-\mathrm{cm}$ thickness (multiplied by 500 in the case of JUc29, assuming an inclusion thickness of $20 \mu \mathrm{m}) ; \varepsilon_{i}$ is the absorption factor, which, for an Mg endmember is estimated to be 100,000 (table 1 of ref. 45); and $t=1 \mathrm{~cm}$ and can be omitted. The conversion factor is given by

$$
K=1,000 * 18 / \rho
$$

where 18 represents $18 \mathrm{~g}$, which is the molar weight of $\mathrm{H}_{2} \mathrm{O}$, and $\rho$ is the density of ringwoodite (taken as $3.9 \mathrm{~g} \mathrm{~cm}^{-3}$ for the $\mathrm{Mg}$ endmember).

Normalized spectra were baseline-corrected (linear background) and integrated in the wavenumber range $3,740-2,600 \mathrm{~cm}^{-1}$. The resulting integrals ranged from 97,500 (spectrum 1) to 107,500 (spectrum 2), yielding water concentrations of 13,500 p.p.m. (1.35 wt\%) for spectrum 1 and 14,884 p.p.m. (1.49 wt\%) for spectrum 2.
These values are probably minima due to beam integration of the $\mathrm{CaSiO}_{3}$ inclusion. Although the uncertainties in the above calculation are difficult to fully quantify, and may be as high as 50\%, we note that simply from comparison of our spectra with those of experimentally synthesized hydrous ringwoodite, the intensity of the $\mathrm{OH}$ absorbance is consistent with water contents of $1 \mathrm{wt} \%$ or more.

34. Brenker, F. E. etal. Carbonates from the lower part of the transition zone or even the lower mantle. Earth Planet. Sci. Lett. 260, 1-9 (2007).

35. Silversmit, G. et al. Polycapillary based $\mu$-XAS and confocal $\mu$-XANES at a bending magnet source of the ESRF. J. Phys. Conf. Ser. 190, 012036 (2009).

36. Yamanaka, $\mathrm{T}$. Crystal structures of $\mathrm{Ni}_{2} \mathrm{SiO}_{4}$ and $\mathrm{Fe}_{2} \mathrm{SiO}_{4}$ as a function of temperature and heating duration. Phys. Chem. Miner. 13, 227-232 (1986).

37. Fujino, K. \& Sasaki, S. X-ray determination of electron distributions in forsterite, fayalite and tephroite. Acta Crystallogr. B 37, 513-518 (1981).

38. Finger, L. W., Hazen, R. M., Zhang, J., Ko, J. \& Navrotsky, A. The effect of Fe on the crystal structure of wadsleyite $\beta-\left(\mathrm{Mg}_{1-x} \mathrm{Fe}_{x}\right)_{2} \mathrm{SiO}_{4}, 0.00 \leq x \leq 0.40$. Phys. Chem. Miner. 19, 361-368 (1993).

39. Nasdala, L. et al. Spectroscopic 2D-tomography: residual pressure and strain around mineral inclusions in diamonds. Eur. J. Mineral. 15, 931-935 (2003).

40. Grimsditch, M. H., Anastassakis, E. \& Cardona, M. Effect of uniaxial stress on the zone-centre optical phonon of diamond. Phys. Rev. $\mathbf{1 8}$ 901-904 (1978).

41. Baonza, V. G., Taravillo, M., Arencibia, A., Caceres, M. \& Nunez, J. Diamond as a pressure sensor in high-pressure Raman spectroscopy using sapphire and other gem anvil cells. J. Raman Spectrosc. 34, 264-270 (2003).

42. Kleppe, A. K., Jephcoat, A. P., Smyth, J. R. \& Frost, D. J. On protons, iron and the high pressure behavior of ringwoodite. J. Geophys. Res. 29, 2021 (2002).

43. Liu, L., Lin, T., Mernagh, P. \& Inoue, T. Raman spectra of hydrous $\gamma-\mathrm{Mg}_{2} \mathrm{SiO}_{4}$ at various pressure and temperatures. Phys. Chem. Miner. 29, 181-187 (2002).

44. Feng, L., Lin, Y., Hu, S., Xu, L. \& Miao, B. Estimating compositions of natural ringwoodite in the heavily shocked Grove Mountains 052049 meteorite from Raman spectra. Am. Mineral. 96, 1480-1489 (2011).

45. Koch-Müller, M. \& Rhede, D. IR absorption coefficients for water in nominally anhydrous high-pressure minerals. Am. Mineral. 95, 770-775 (2010).

46. Matveev, S. \& Stachel, T. FTIR spectroscopy of OH in olivine: a new tool in kimberlite exploration. Geochim. Cosmochim. Acta 71, 5528-5543 (2007)

47. Libowitzky, E. \& Rossman, G. R. Principles of quantitative absorbance measurements in anisotropic crystals. Phys. Chem. Miner. 23, 319-327 (1996). 

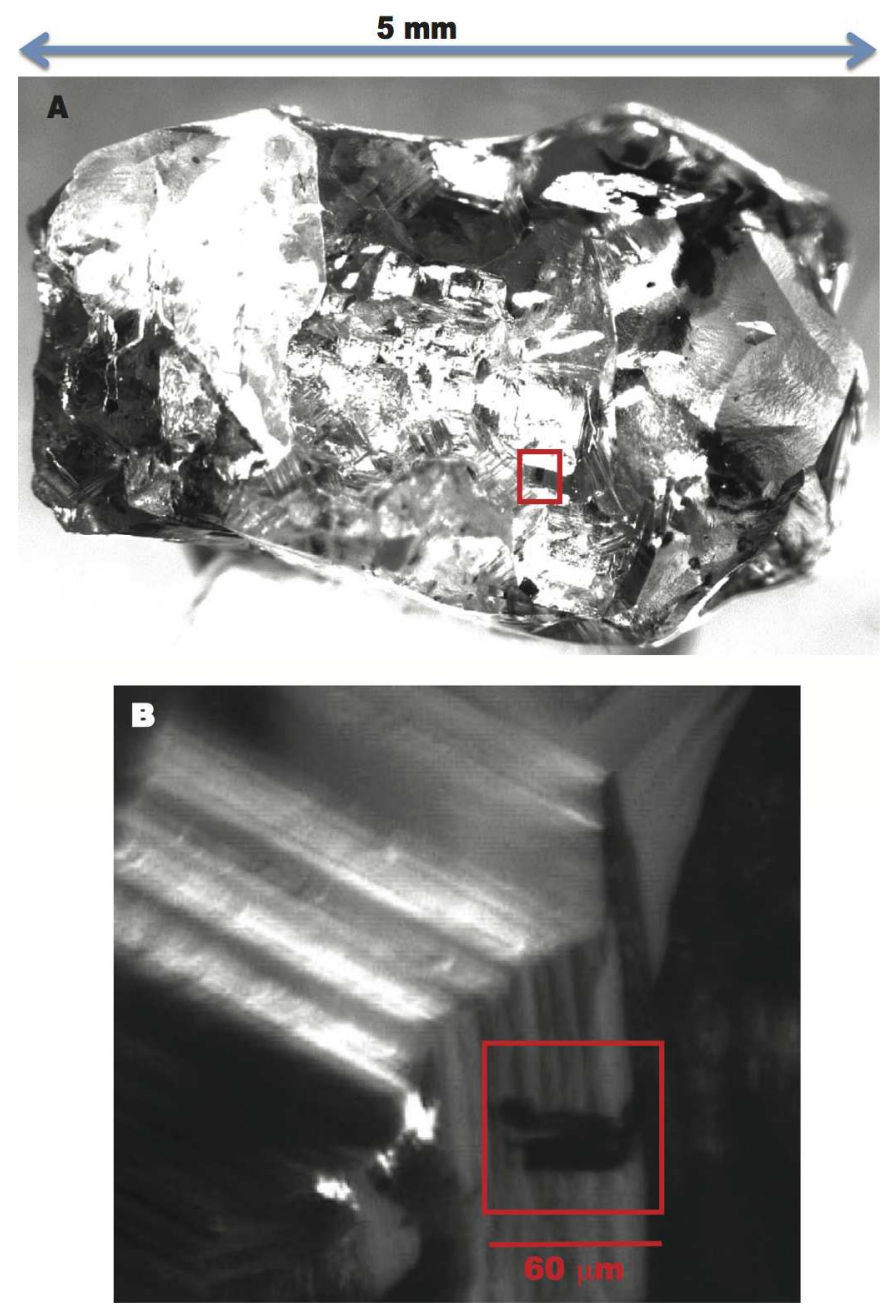

Extended Data Figure $1 \mid$ Image of JUc29 diamond and the ringwooditewalstromite inclusion. a, Monochrome image of diamond JUc29 taken under incident light, with the ringwoodite-walstromite inclusion pair highlighted by a red square. The irregular shape and hexagonal pits in the diamond are signs of significant resorption. $\mathbf{b}$, Enlarged view of the area of the host diamond (rotated $90^{\circ}$ relative to a) containing the ringwooditewalstromite inclusion pair. The shadow behind the rectangular area outlining the inclusion pair is probably a stress fracture in the diamond. 


\section{RESEARCH LETTER}

Extended Data Figure $2 \mid$ Three-dimensional confocal $\mu$ XRF view of two-phase ringwoodite-walstromite inclusion. Three-dimensional confocal $\mu \mathrm{XRF}$ view of two-phase inclusion within JUc29 diamond, showing

$\mathrm{Ca}$ (red) and $\mathrm{Fe}$ (green) low-intensity isosurfaces for confocal $\mu \mathrm{XRF}$, with

blue representing the diamond host (derived from scatter intensity). Scale bar, $40 \mu \mathrm{m}$. 


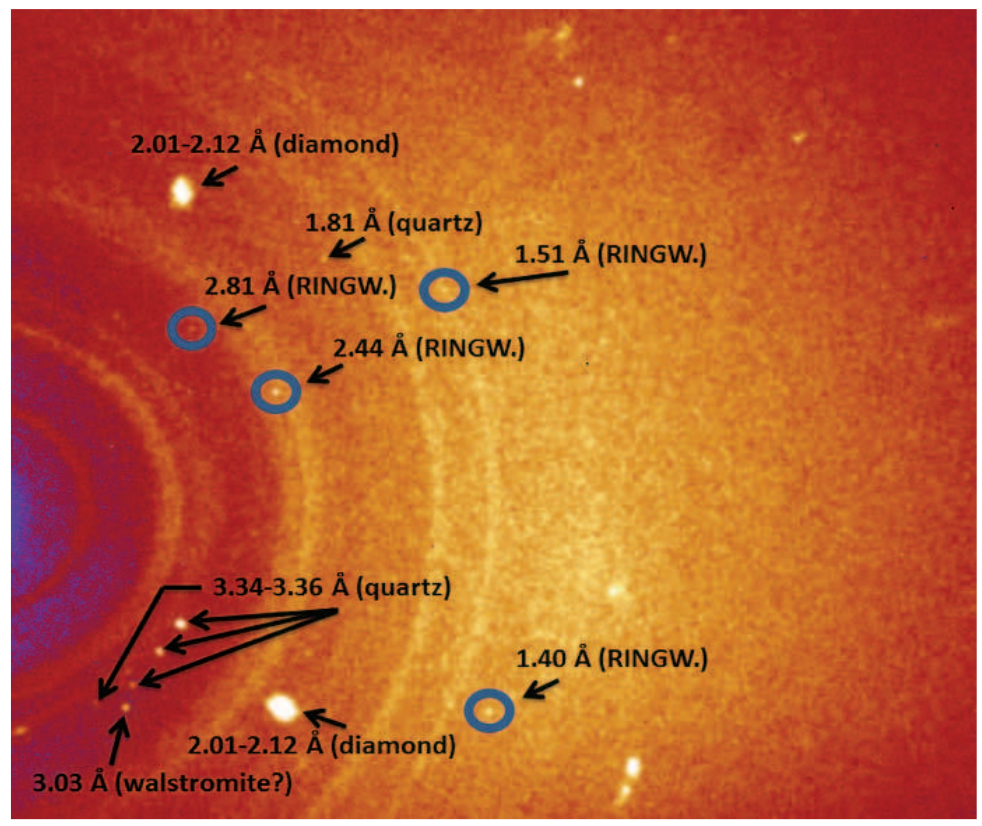

Extended Data Figure $3 \mid$ Single-crystal X-ray diffraction image showing the main diffraction peaks of ringwoodite. CCD image collected by a STOE STADI IV single-crystal diffractometer, using monochromatized $\mathrm{Mo}_{\mathrm{K} \alpha}$ radiation $(\lambda=0.71073 \AA)$, working at $50 \mathrm{kV}$ and $40 \mathrm{~mA}$ and with an exposure time of $60 \mathrm{~s}$. The image shows the main four diffraction peaks of ringwoodite (outlined by blue circles and labelled "RINGW" for clarity), that is, the planes (113) at $2.44 \AA,(440)$ at $1.40 \AA,(220)$ at $2.81 \AA$ and (115) at $1.51 \AA$, in their exact order of expected relative intensity, which is well determined by CCD. The expected fifth peak, at about $2.02 \AA$, was not found because it is covered by the very intense diamond peak, which occurs at the same $d$ spacing (large and bright peaks in figure). In addition to the ringwoodite diffraction peaks, the main peaks of the host diamond are present as the most intense peaks (labelled 'diamond'). The characteristic peaks of quartz are evident (labelled 'quartz'). Secondary quartz crystals occur in resorption pits on the sample surface but quartz is not included within the diamond. The diffraction rings result from clay minerals again present on the surface of the diamond. Finally, at least one diffraction peak, that occurring at $3.03 \AA$, probably results from $\mathrm{CaSiO}_{3}$-walstromite (labelled 'walstromite?'). 